\title{
Nanoparticle-based vaccine development and evaluation against viral infections in pigs
}

\author{
Santosh Dhakal ${ }^{1,2}$ and Gourapura J. Renukaradhya ${ }^{1,2^{*}}$ (]
}

\begin{abstract}
Virus infections possess persistent health challenges in swine industry leading to severe economic losses worldwide. The economic burden caused by virus infections such as Porcine Reproductive and Respiratory Syndrome Virus, Swine influenza virus, Porcine Epidemic Diarrhea Virus, Porcine Circovirus 2, Foot and Mouth Disease Virus and many others are associated with severe morbidity, mortality, loss of production, trade restrictions and investments in control and prevention practices. Pigs can also have a role in zoonotic transmission of some viral infections to humans. Inactivated and modified-live virus vaccines are available against porcine viral infections with variable efficacy under field conditions. Thus, improvements over existing vaccines are necessary to: (1) Increase the breadth of protection against evolving viral strains and subtypes; (2) Control of emerging and re-emerging viruses; (3) Eradicate viruses localized in different geographic areas; and (4) Differentiate infected from vaccinated animals to improve disease control programs. Nanoparticles (NPs) generated from virus-like particles, biodegradable and biocompatible polymers and liposomes offer many advantages as vaccine delivery platform due to their unique physicochemical properties. NPs help in efficient antigen internalization and processing by antigen presenting cells and activate them to elicit innate and adaptive immunity. Some of the NPs-based vaccines could be delivered through both parenteral and mucosal routes to trigger efficient mucosal and systemic immune responses and could be used to target specific immune cells such as mucosal microfold (M) cells and dendritic cells (DCs). In conclusion, NPs-based vaccines can serve as novel candidate vaccines against several porcine viral infections with the potential to enhance the broader protective efficacy under field conditions. This review highlights the recent developments in NPs-based vaccines against porcine viral pathogens and how the NPs-based vaccine delivery system induces innate and adaptive immune responses resulting in varied level of protective efficacy.
\end{abstract}

\section{Table of Contents}

1 Economically important viral infections of pigs

1.1 Diseases caused by RNA viruses

1.2 Diseases caused by DNA viruses

2 Vaccination against porcine viral infections

3 Importance of nanoparticle-based vaccine delivery platforms

4 Particulate vaccines and porcine viral infections

4.1 Virus-like particles (VLPs)

4.2 Biodegradable synthetic PLGA NPs
4.3 Polyanhydride-based NPs

4.4 Polysaccharide-based NPs

4.5 Liposome-based NPs

5 Conclusions and future perspectives

References

*Correspondence: gourapura.1@osu.edu

2 Department of Veterinary Preventive Medicine, College of Veterinary

Medicine, The Ohio State University, Columbus, OH 43210, USA

Full list of author information is available at the end of the article 


\section{Economically important viral infections of pigs}

Viruses are the obligate intracellular nano-sized particles, which depend on host cell machinery for propagation and survival. They carry deoxyribonucleic acid (DNA) or ribonucleic acid (RNA) as their genomic material. There are several viruses from both DNA and RNA virus families that infect and produce disease in pigs [1]. There are many economically important swine viral infections which cause considerable morbidity and mortality, and responsible for significant economic losses to the pork industry (Table 1). Depending on their cellular and tissue tropisms, viruses cause pathological changes and clinical signs associated with respiratory system, reproductive and gastrointestinal tracts, nervous system, skin and extremities, alone or in combinations $[1,2]$.

\subsection{Diseases caused by RNA viruses}

Porcine reproductive and respiratory syndrome virus (PRRSV), an enveloped and positive-stranded RNA virus of Arteriviridae family, causes porcine reproductive and respiratory syndrome (PRRS) [3]. PRRS is responsible for over one billion dollar loss per year through direct and indirect costs in the US swine industry [4]. Two entirely distinct genotypes of PRRSV circulate in European (genotype 1/PRRSV 1) and North American countries (genotype 2/PRRSV 2) and cause tremendous economic loss. PRRSV is transmitted through oral-nasal secretions and semen. The clinical signs include fever, anorexia, mild to severe respiratory problems, abortion and reproductive failures. It is the most common pathogen associated with porcine respiratory disease complex (PRDC) [3].

Swine influenza (flu) constitutes another persistent health challenge to the global pig industry. Flu infection is caused by influenza A virus of Orthomyxoviridae family which has negative-sense, single-stranded, segmented RNA genome. Influenza virus is transmitted through direct contact with infected animals or contaminated fomites, aerosols and large droplets [5]. The clinical signs of influenza infection include fever, anorexia, loss of weight gain and respiratory problems. Influenza associated economic losses are due to morbidity, loss of body weight gain, increased time to market, secondary infections, medication and veterinary expenses [6]. Influenza of swine origin occasionally infect humans and can even lead to pandemics as of 2009 [7].

Porcine epidemic diarrhea virus (PEDV), transmissible gastroenteritis virus (TGEV) and porcine deltacoronavirus (PDCoV) are enteric pathogens of young pigs [8]. These viruses belong to Coronaviridae family and have positive-sense, single-stranded RNA genome. TGEV did serious economic damage to the swine industry in 1990s but with the advent of vaccines it has been largely controlled [8]. PEDV still results in high morbidity and mortality in neonatal piglets with clinical signs like severe diarrhea, vomiting, dehydration and death. In 2013/14, PEDV outbreak in the US led to over a billion-dollar loss

Table 1 Economically important viral diseases of pigs

\begin{tabular}{|c|c|c|c|c|}
\hline Disease & Virus & Epidemiology & Clinical signs & References \\
\hline $\begin{array}{l}\text { Porcine reproductive and respira- } \\
\text { tory syndrome (PRRS) }\end{array}$ & $\begin{array}{l}\text { PRRS virus (PRRSV) } \\
\text { Single strand (+) RNA }\end{array}$ & Worldwide & $\begin{array}{l}\text { Fever, anorexia, mild to severe } \\
\text { respiratory problems, abortion, } \\
\text { reproductive failures }\end{array}$ & {$[3]$} \\
\hline Swine influenza & $\begin{array}{l}\text { Influenza A virus (IAV) } \\
\text { Single strand (-) RNA }\end{array}$ & Worldwide & $\begin{array}{l}\text { Fever, anorexia, loss of weight } \\
\text { gain, respiratory problems }\end{array}$ & {$[5,28]$} \\
\hline Porcine epidemic diarrhea (PED) & $\begin{array}{l}\text { PED virus (PEDV) } \\
\text { Single strand }(+) \text { RNA }\end{array}$ & Worldwide & $\begin{array}{l}\text { Severe diarrhea, vomiting and } \\
\text { dehydration }\end{array}$ & {$[115]$} \\
\hline Foot and mouth disease (FMD) & $\begin{array}{l}\text { FMD virus (FMDV) } \\
\text { Single strand }(+) \text { RNA }\end{array}$ & $\begin{array}{l}\text { Parts of Asia, Africa, Middle East } \\
\text { and South America }\end{array}$ & $\begin{array}{l}\text { Fever, inappetence, vesicular } \\
\text { lesions on extremities }\end{array}$ & {$[11]$} \\
\hline $\begin{array}{l}\text { Classical swine fever (CSF)/hog } \\
\text { cholera }\end{array}$ & $\begin{array}{l}\text { CSF virus (CSFV) } \\
\text { Single strand }(+) \text { RNA }\end{array}$ & $\begin{array}{c}\text { Endemic in Central America, Africa, } \\
\text { Asia and parts of South America }\end{array}$ & $\begin{array}{l}\text { Fever, anorexia, erythema, respira- } \\
\text { tory signs, neurological signs, } \\
\text { reproductive failures, death }\end{array}$ & {$[13]$} \\
\hline $\begin{array}{l}\text { Porcine circovirus associated } \\
\text { disease (PCVAD) }\end{array}$ & $\begin{array}{l}\text { Porcine circovirus } 2 \text { (PCV2) } \\
\text { Single strand DNA }\end{array}$ & Worldwide & $\begin{array}{l}\text { Poor weight gain, respiratory } \\
\text { problems, dermatitis, enteritis, } \\
\text { nephropathy, reproductive } \\
\text { failures }\end{array}$ & {$[16]$} \\
\hline Porcine parvovirus infection & $\begin{array}{l}\text { Ungulate parvovirus } 1 \\
\text { Single strand DNA }\end{array}$ & Worldwide & $\begin{array}{l}\text { Stillbirth, mummification, embry- } \\
\text { onic death, infertility }\end{array}$ & [17] \\
\hline Pseudorabies/Aujeszky's disease & $\begin{array}{l}\text { Suid herpesvirus } 1 \\
\text { Double strand DNA }\end{array}$ & $\begin{array}{l}\text { China and parts of Europe, Asia } \\
\text { and Latin America }\end{array}$ & $\begin{array}{l}\text { Nervous disorders, respiratory } \\
\text { problems, weight loss }\end{array}$ & {$[18,19]$} \\
\hline African swine fever (ASF) & $\begin{array}{l}\text { ASF virus (ASFV) } \\
\text { Double strand DNA }\end{array}$ & $\begin{array}{l}\text { Endemic in sub-Saharan Africa, } \\
\text { Sardinia, Caucasus region and } \\
\text { Eastern Europe }\end{array}$ & $\begin{array}{l}\text { Fever, anorexia, erythema, respira- } \\
\text { tory signs, reproductive failures, } \\
\text { death }\end{array}$ & {$[13]$} \\
\hline
\end{tabular}


[9]. Rotaviruses are double-stranded RNA viruses of Reoviridae family, cause enteric infections in pigs. Rotavirus of groups $\mathrm{A}, \mathrm{B}, \mathrm{C}, \mathrm{E}$ and $\mathrm{H}$ are involved in porcine enteric infections. Some of these porcine rotaviruses also have zoonotic potential [10].

Foot and mouth disease (FMD) is another highly contagious, acute viral disease in pigs. The etiologic agent, FMD virus (FMDV), is a positive-sense, single-stranded RNA virus of Picornaviridae family [11]. FMDV is transmitted through direct contact with infected animals or contaminated sources. Clinical signs include high fever, appearance of vesicular lesions on the extremities, salivation, lameness and death. FMDV causes frequent epizootics in many parts of the world resulting in severe economic loss, food insecurity and trade restrictions [11].

Classical swine fever (CSF) or hog cholera can result in high morbidity and mortality in pigs. It is caused by CSF virus (CSFV), an enveloped, positive-sense, singlestranded virus of Flaviviridae family. Transmission of CSFV occurs through oral-nasal routes after contact with infected pigs or contaminated resources and even vertically from infected sows to piglets [12]. Clinical signs include fever, anorexia, respiratory problems, neurological disorders, reproductive failures and death. CSF is a notifiable disease to World Organization for Animal Health (OIE). The economic losses are associated with production loss, trade limitations and tremendous expenditures in eradication programs [13]. For example, the 1997/98 outbreak of CSFV in the Netherland resulted in death of 9 million pigs and economic losses of 2.3 billion dollars [14]. United States is free of CSFV; however, this virus is endemic in many parts of the world including Central and South America, Africa and Asia.

\subsection{Diseases caused by DNA viruses}

Porcine circovirus 2 (PCV2), a single-stranded DNA virus of Circoviridae family, causes multi-systemic disease referred as porcine circovirus-associated disease (PCVAD). PCV2 is transmitted horizontally as well as vertically. Direct contact is the most efficient way of horizontal transmission of this virus. The clinical signs of PCV2 infection include poor weight gain, respiratory problems, dermatitis, enteritis, nephropathy and reproductive failures [15]. Five genotypes of PCV2 (PCV2a to PCV2e) are identified and circulate with high prevalence in swine herds causing significant economic losses worldwide [16].

Porcine parvovirus (PPV) is the common cause of reproductive failure in swine herds. This single-stranded DNA virus of Parvoviridae family is transmitted through oral-nasal routes. Stillbirths, mummification, embryonic death, and infertility (SMEDI syndrome) are linked to PPV infection. Conventionally, PPV was considered genetically conserved but recent evidences suggest that several virulent strains have emerged due to its high mutation rate [17].

Aujeszky's disease or pseudorabies in pigs is caused by Suid herpesvirus 1, a double stranded DNA virus belonging to Herpesviridae family. The causative agent is spread primarily through direct animal-to-animal (nose-to-nose or sexual) contact. Pseudorabies is characterized by nervous disorders, respiratory problems, weight loss, deaths in younger piglets and reproductive failures; and is one of the most devastating infectious diseases in pig industry $[18,19]$.

African Swine Fever (ASF) causes hemorrhagic infection with high morbidity and mortality. The etiologic agent, ASF virus (ASFV), is a double stranded DNA virus of Asfarviridae family [20]. Virus transmission occurs through direct contact with infected animals, indirect contacts with fomites or through soft tick species of the genus Ornithodoros. Clinical disease may range from asymptomatic infection to death with no signs. Acute infections are characterized by high fever, anorexia, erythema, respiratory distress, reproductive failure in pregnant females and death [20]. ASF is OIE notifiable disease. United States is free of ASFV, however, this virus is endemic in domestic and wild pig population in many parts of the world with possibility of transmission to the US and other nonendemic regions through animal trades [13]. The economic losses are associated with production loss, trade limitations and tremendous expenditures in eradication programs [13].

Besides the RNA and DNA viruses described above, many other emerging and re-emerging viruses such as porcine hepatitis $E$ virus, porcine endogenous retrovirus, porcine sapovirus, Japanese encephalitis virus, encephalomyocarditis virus and others cause variable degree of impact in swine health and economic losses in pig industry globally $[2,21,22]$.

\section{Vaccination against porcine viral infections}

Different types of vaccines that are available against economically important swine viruses are listed in Table 2. Vaccines against PRRSV are being used in the US since 1980 s [23]. Both inactivated and modified-live virus vaccines are available and used globally. These vaccines are effective in reducing clinical disease and viremia mainly against homologous but not against heterologous infections [24]. Therefore, different strategies are ongoing to develop live, inactivated, subunit and mucosal PRRSV vaccines to induce better immunity and broader protection [23, 25-27]. Swine influenza vaccines are also most effective when the vaccine strains closely match with the circulating strains $[5,28]$. 
Table 2 Vaccines available against economically important porcine viral infections

\begin{tabular}{|c|c|c|c|}
\hline Disease & Vaccines available & Improvements needed & References \\
\hline $\begin{array}{l}\text { Porcine reproductive and respiratory syndrome } \\
\text { (PRRS) }\end{array}$ & Inactivated, modified-live virus & $\begin{array}{l}\text { Rapid immune induction } \\
\text { Heterologous protection } \\
\text { No adverse impact on health }\end{array}$ & {$[23,24]$} \\
\hline Swine influenza & Inactivated, modified-live virus & $\begin{array}{l}\text { Broader protection } \\
\text { No maternal antibody interference } \\
\text { No vaccine-enhanced disease }\end{array}$ & {$[5,28]$} \\
\hline Porcine epidemic diarrhea (PED) & $\begin{array}{l}\text { RNA particle, inactivated and } \\
\text { live-attenuated virus (in Asia) }\end{array}$ & $\begin{array}{l}\text { Protective immune response in sows } \\
\text { Better mucosal immunity }\end{array}$ & {$[8,9]$} \\
\hline Foot and mouth disease (FMD) & Inactivated virus & $\begin{array}{l}\text { Less stringent requirements in vaccine produc- } \\
\text { tion } \\
\text { Protection against multiple serotypes }\end{array}$ & {$[29]$} \\
\hline Classical swine fever (CSF) & Live-attenuated virus & DIVA potential & {$[30]$} \\
\hline Porcine circovirus associated disease (PCVAD) & Inactivated, recombinant subunit & Multi-genotype protection & {$[16,31]$} \\
\hline Porcine parvovirus infection & Inactivated virus & Protection against novel strains & {$[17,33]$} \\
\hline Pseudorabies & Inactivated, live-attenuated virus & Protection against novel emerging strains & {$[18,19]$} \\
\hline African swine fever (ASF) & None & Novel cross-protective vaccine & {$[20]$} \\
\hline
\end{tabular}

To increase the immunity and protection, vaccines containing multiple strains of influenza A virus (IAV) and autogenous vaccines are widely used $[5,28]$. Cocirculation of multiple lineages of IAV and frequent antigenic drift are responsible for reduced field efficacy of current swine influenza vaccines. Moreover, the most commonly used whole inactivated IAV vaccines administered via intramuscular route do not induce adequate mucosal antibody and cellular immune responses, suffer maternal antibody interference in young piglets and even can cause enhanced respiratory disease $[5,28]$.

The emergence of highly virulent strains of PEDV in recent years has highlighted the need of safe and effective vaccines against porcine enteric coronaviruses that prevents clinical disease, mortality and virus shedding in neonates [8]. Modified live vaccines against rotavirus are available for use in pigs against rotavirus A but their efficacy under field conditions is questionable indicating the need of alternatives for porcine rotavirus management [10].

The available inactivated vaccines provided great help in prevention and control of FMD outbreaks in many countries. However, the development of these vaccines needs high level biocontainment facilities. Further, the FMDV serotypes undergo continuous antigenic drift and escape the vaccine-induced immunity [29]. Thus, FMD vaccines with less stringent regulatory procedures and multi-serotype protective efficacy are needed in the future. Safe and highly efficacious live-attenuated vaccines are available against CSFV but differentiation of infected from vaccinated animals (DIVA) is not possible with these vaccines, which limit their use during outbreak control or disease eradication programs [30].
Inactivated whole virus or subunit vaccines based on PCV2a are highly adopted in pig farms and are efficacious in reducing clinical signs and improving the production parameters. However, infections are still widespread in vaccinated farms $[16,31]$. Further, the replacement of PCV2a to PCV2b and recently to PCV2d is in part contributed by the selection pressure exhibited by PCV2a-based vaccines [32] which highlights the need of vaccines that protect against multiple genotypes.

The currently used inactivated vaccines of porcine parvo virus protect against old PPV strains but not against the newly emerging strains demanding for more efficacious vaccines [17, 33]. Fortunately, pseudorabies has been eradicated in many countries including the US by using inactivated and attenuated vaccines together with stringent biosecurity measures. However, it is still a problematic disease in many countries including China and is also maintained in feral swine populations in other countries $[18,34]$. The frequent emergence of virulent strains even in the vaccinated herds demands updated vaccine technology to achieve efficient control and ultimate global eradication of pseudorabies [19, 34].

Vaccine is not available so far against ASFV, and the control measures depend entirely on early identification and culling of infected herds and adoption of strict sanitary measures [35]. Vaccine development is hindered by the antigenic diversity and multitude of immune-evasion strategies used by the virus. An effective vaccine will definitely help in control and eradication of ASFV from endemic countries and prevent its geographical expansion [20]. 


\section{Importance of nanoparticle-based vaccine delivery platforms}

Development of vaccines has made significant impact on reducing the viral infectious disease burden in both humans and animals. However, there are still many diseases for which either we do not have vaccines or need substantial improvements over existing ones [36, 37]. In the past few decades, nanoparticles (NPs)-based technologies have elicited significant interests in the development of novel vaccine candidates as they offer multiple benefits over inactivated virus or subunit soluble antigens. NPs-based vaccines (nanovaccines) are prepared either by encapsulating vaccine components within the NPs or by decorating the particle surface with viral antigens. NPs protect antigens from proteolytic degradation, prolong their bioavailability and maintain slow and sustained antigen release. All of these properties help in induction of better immune responses compared to soluble antigen vaccines [38]. The different mechanisms used by various NPs to facilitate immune modulation of antigen presenting cells (APCs) are depicted graphically in Figure 1. Briefly, NPs can enhance antigen adsorption and uptake by APCs; they can also facilitate antigen processing mechanisms; NPs can induce maturation of DCs and promote antigen cross-presentation through major histocompatibility complex (MHC) class I to $\mathrm{CD} 8^{+} \mathrm{T}$ cells; and induce production of different innate cytokines that regulate humoral and cellular immune responses. NPs-loaded antigens are readily phagocytosed by APCs; soluble antigens are not [39]. Moreover, dendritic cells (DCs), the key player involved in bridging innate and adaptive immunity, preferentially internalize NPs compared to microparticles (>1000 nm). For example, when poly(lactic-co-glycolic acid) (PLGA) particles of size
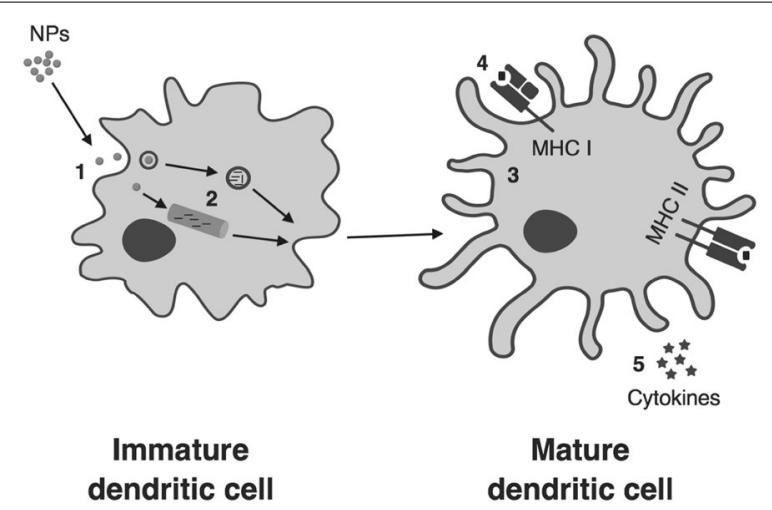

Figure 1 Schematic representation of different effects imparted by NPs on APCs. NPs-based vaccines can-(1) enhance antigen uptake; (2) facilitate antigen processing; (3) induce maturation of DCs; (4) promote antigen cross-presentation by $\mathrm{MHC}-\mathrm{I}$; and (5) induce cytokine production.
$300 \mathrm{~nm}$ to $17 \mu \mathrm{m}$ encapsulating ovalbumin were tested on mouse bone-marrow derived dendritic cells, $300 \mathrm{~nm}$ sized particles were taken up efficiently compared to larger ones [40]. The $300 \mathrm{~nm}$ sized PLGA NPs resulted in greater activation of DCs and stronger antigen-specific T cells responses in immunized mice compared to soluble antigens and larger particles [40].

Besides controlled delivery of antigens, NPs also provide adjuvant-like functions. Vaccine adjuvants either work as antigen delivery systems facilitating antigen uptake and presentation by APCs or they activate innate immune receptors for cytokine production and maturation/migration of DCs [41]. Adjuvant-induced innate immune responses determine the type of adaptive immune responses generated such as $\mathrm{T}$ helper 1 (Th1) versus $\mathrm{T}$ helper 2 (Th2)-biased immunity [42]. Alum, the most widely used adjuvant in humans, is safe and inexpensive. Its compatibility has been proved favorable with different vaccine antigens. However, despite inducing potent antibody responses, alum is a weak-inducer of cell-mediated immunity. Adverse reactions are observed at injection site with alum-based adjuvants [43, 44]. In veterinary vaccines, oil-in-water emulsions or saponins are the most common adjuvants. These can also cause adverse reactions at the injection sites [45, 46]. While number of adjuvants are available for parenteral vaccinations, very limited options are available for intranasal (IN) or other alternative routes of immunization [41, 47, 48]. NPs can serve as an alternative adjuvant for human and animal use as they act both as antigen delivery system and activate the innate immune responses [49-51]. Further, the modern vaccination approach has shifted from traditional whole pathogen-based antigens to small fraction (subunit) of the pathogen. However, purified whole inactivated pathogen and subunit or recombinant antigens by themselves are poorly immunogenic and require a potent immunostimulatory platform to augment the immune response. This can be achieved through NPs-based technologies [47, 52].

NPs-based platforms can be used to deliver multiple antigens or antigen/adjuvant combinations, which improves antigen uptake and concurrent activation of APCs leading to innate immune programming $[53,54]$. Co-delivery of $\mathrm{CpG}$ oligodeoxynucleotide and tetanus toxoid in nanospheres induced significantly greater $\mathrm{T}$ cell proliferative response and 5 to 16 times greater IgG antibody isotypes in mice after subcutaneous immunization compared with the group that received tetanus toxoid and CpG oligodeoxynucleotide in soluble form [54]. Likewise, co-delivery of melanoma antigen and Toll-like receptor (TLR) 4 agonist in PLGA NPs induced therapeutic anti-tumor effects that are mediated through potent $\mathrm{CD}^{+} \mathrm{T}$ cell activation [55]. NPs can be surface modified 
to target microfold (M) cells, macrophages or DCs, and could be used for mucosal vaccination through oral, nasal or other mucosal routes of immunization. In mice, surface coating of PLGA NPs encapsulating hepatitis B virus vaccine antigens with lectin resulted in efficient targeting of oral delivered NPs to mucosal M cells and induced secretary IgA antibody response in mucosal surfaces [56]. Likewise, DCs targeted chitosan NPs loading plasmid DNA encoding nucleocapsid protein of Severe Acute Respiratory Syndrome Coronavirus (SARS-CoV) induced better nucleocapsid protein-specific mucosal IgA antibody response compared to soluble unentrapped antigens after nasal immunization in mice [57].

A targeted T-cell mediated immune response is critical in protection against intracellular pathogens such as viruses. Beneficially, NPs-delivered antigens are useful in antigen cross-presentation to cytotoxic $\mathrm{T}$ lymphocytes (CTLs) and development of robust cell-mediated immune response $[58,59]$. PLGA-based particulate vaccines are shown to induce efficient T-cell immunity in mice and pigs [60-63]. Similarly, rodent and pig studies have shown that polyanhydride NPs-based vaccines also enhance cellular immunity $[50,64]$. Thus, immunogenic properties of different polymer-based NPs could be exploited to improve the efficacy of vaccines for use against porcine viral infections.

\section{Particulate vaccines and porcine viral infections}

In this review, only studies conducted in pigs related to the development and evaluation of NPs-based vaccine candidates by using virus-like particles (VLPs), biodegradable polymers, polysaccharides and liposomes against porcine viral infections are included (Table 3).

\subsection{Virus-like particles (VLPs)}

VLPs are constructed using viral structural proteins, which can self-assemble but are non-infectious as they lack the viral genomic material. VLPs mimic the virion and can effectively induce innate and adaptive immune responses [65]. VLPs are produced using different bacterial, insect, yeast or mammalian expression systems [66]. Due to their smaller size and particulate nature, VLPs-based vaccines are processed and presented not only through MHC class II but also through MHC class I pathway leading to the generation of antibodies as well as CTL responses $[67,68]$. The potential use of VLPs in porcine viral vaccine development is evident through the success in commercialization of Human Papilloma Virus (HPV), Hepatitis B virus and malaria vaccines by adapting this technology [69].

In one study, PRRSV VLPs containing five (GP5, GP4, GP3, GP2a and M) and two (GP5 and M) viral surface proteins were generated using the baculovirus expression system. PRRSV VLPs vaccine was mixed at 1:1 ratio with Mycobacterium tuberculosis whole cell lysate (M. tuberculosis WCL) adjuvant and administered INto pigs. VLPs-vaccinated pigs were partially protected with 2-log reduction of virus titers in lungs. VLPs-vaccinated pigs also had enhanced IFN- $\gamma$ response compared to mock challenge pigs [70]. However, in another study, when pigs were vaccinated IN with PRRSV VLPs expressing N, M, GP5 and E proteins, enhanced viremia accompanied with higher level of IFN- $\alpha$ cytokine response was observed [71]. The contrasting results in PRRSV VLPs study suggest the need for further research to fully evaluate the potential of VLPs-based PRRSV vaccines for swine.

Influenza-associated VLPs expressing HA, NA and M1 proteins of pandemic 2009 (H1N1) virus were inoculated twice intramuscularly with or without Emulsigen (MVP Lab, USA) adjuvant to pigs. This vaccine induced robust serum IgG, mucosal IgA and virus neutralizing antibody responses in pigs. After homologous virus challenge, VLPs-vaccinated pigs had significantly reduced pneumonic lesions and virus titers were substantially lowered in upper and lower respiratory tracts compared to mock vaccinated animals [72].

Many studies have been conducted with the goal to develop VLPs-based FMDV vaccine using various expression systems encoding different viral antigens. Rabbit hemorrhagic disease virus (RHDV) VLPs expressing T-cell epitope of 3A protein of FMDV (RHDV-3A-VLPs) was generated. This VLPs vaccine induced maturation of bone marrow derived dendritic cells in vitro [73]. Pigs immunized IM with RHDV-3A-VLPs together with Montanide ISA 206 adjuvant (Seppic, France) induced higher serum IgG and IgA antibody responses. This vaccine also increased number of IFN- $\gamma$ secreting cells and lymphoproliferative responses in PBMCs compared to vaccine delivered without adjuvant and IN RHDV-3A-VLPs inoculated pigs; however, challenge experiments were not performed [73]. Guo et al. constructed FMDV VLPs expressing capsid proteins VP0, VP1 and VP3 and immunized pigs by IM route [74]. VLPs-vaccinated pigs produced virus-specific neutralizing antibodies and IFN- $\gamma$ response in peripheral blood mononuclear cells (PBMCs) as good as the inactivated FMDV vaccine control. After challenge with homologous virus, VLPs-vaccinated pigs did not show specific clinical signs [74]. In another study, VP1 epitope peptides (EP141-160) of FMDV were inserted into the coat protein genes of male-specific coliphage (MS2) (CP-EP141-160 VLPs) and injected IM to pigs. This formulation resulted in induction of virus neutralizing antibodies and protected $60 \%$ of the immunized pigs compared to only $20 \%$ protection in peptide alone vaccinated animals. However, the protection was lower than inactivated vaccine $(80 \%)$ indicating the need 


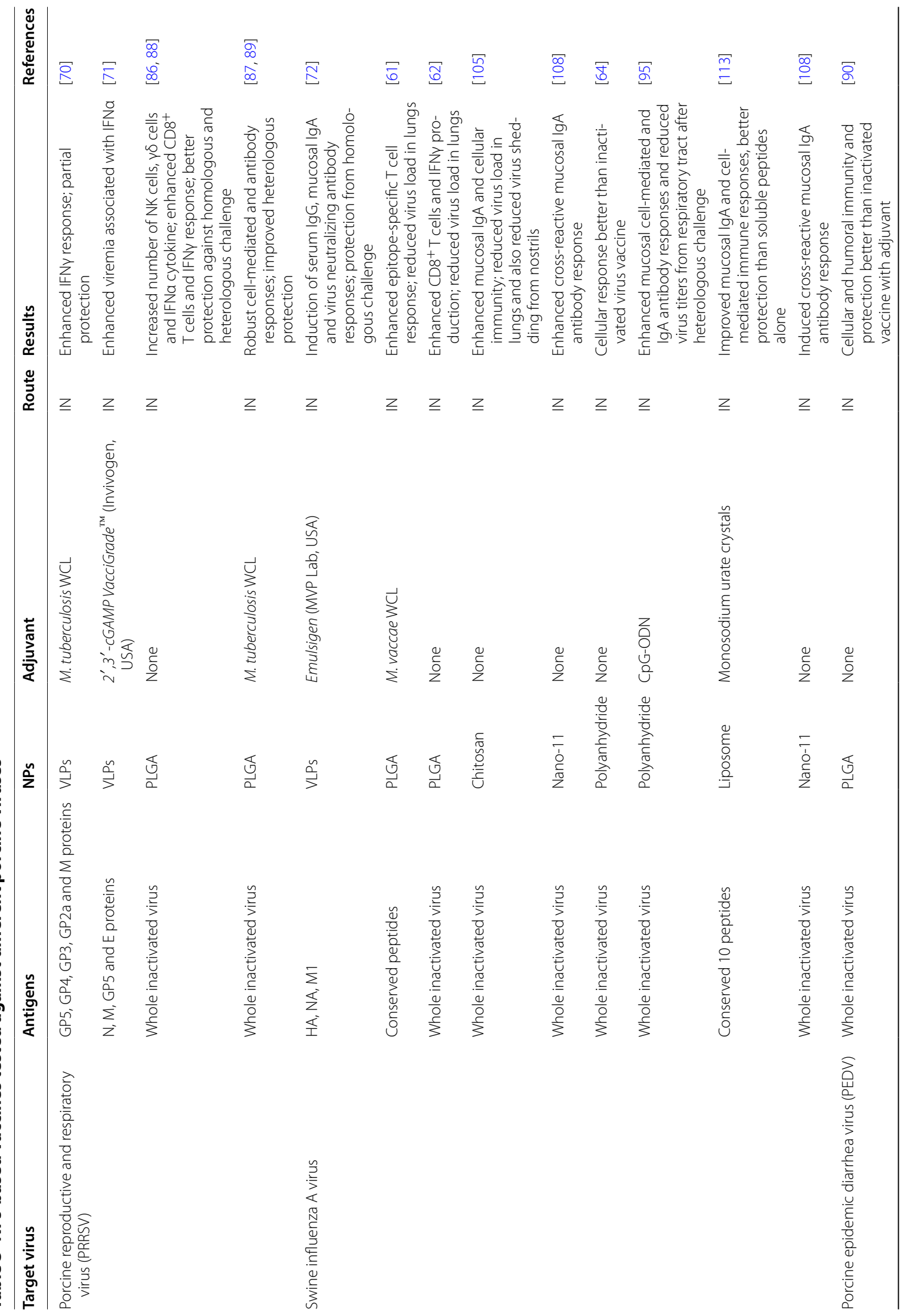




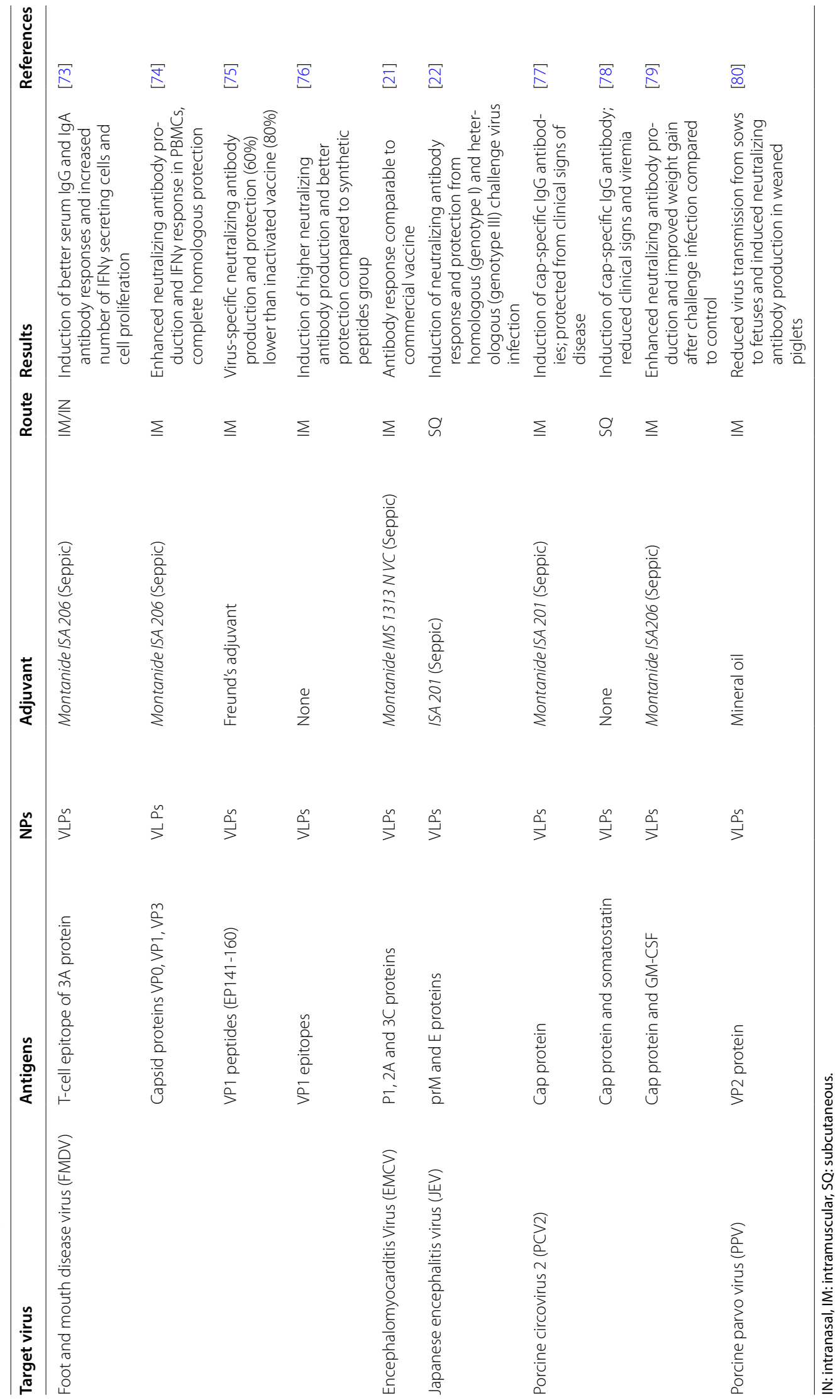


of further improvement in this VLPs either by using longer sequence of epitope or addition of other adjuvants [75]. VLPs generated by insertion of VP1 epitopes of FMDV into porcine parvovirus VP2 were administered IM to pigs. This VLPs-vaccine induced higher virus neutralizing antibodies compared to synthetic peptide vaccine and resulted in better protection to challenge FMDV infection [76].

VLPs have also been developed and tested against porcine neurotropic viruses [21, 22]. Porcine encephalomyocarditis virus (EMCV) VLPs containing structural protein $\mathrm{P} 1$, nonstructural protein $2 \mathrm{~A}$ and protease $3 \mathrm{C}$ were generated. After IM administration together with Montanide IMS 1313 N VG adjuvant (Seppic), VLPs-vaccine induced sustained production of virus neutralizing antibodies comparable to commercial vaccine control. There was absence of any severe injection site reactions in VLPs-vaccinated pigs [21]. This suggests the potential of developing VLPs-based vaccine against EMCV disease in pigs. Likewise, in a recent study, Japanese encephalitis virus genotype I (GI) VLPs encoding premembrane (prM) and envelope (E) proteins were constructed. After subcutaneous immunization, this vaccine formulation induced robust neutralizing antibody response and protection against both homologous GI and heterologous GIII JEVs viruses. This finding indicates the cross-protection potential of VLPs-based JEV vaccine in pigs [22].

Early study on PCV2 VLPs used full length Cap protein in Escherichia coli expression system [77]. Pigs vaccinated against PCV2 using Cap VLPs and ISA 201 adjuvant (Seppic) by IM route induced Cap-specific IgG antibodies. Vaccinated animals were apparently healthy with normal body weight gain and absence of any clinical signs of disease [77]. Li et al. [78] showed induction of Cap-specific IgG antibodies in pigs vaccinated by subcutaneous (SC) injection of Cap VLPs. Vaccinated pigs demonstrated reduced fever, viremia and mild pathological changes in lungs and lymph nodes compared to unvaccinated challenge animals. In another study, VLPs co-expressed with Cap protein and porcine GM-CSF were administered IM to pigs. This vaccine formulation induced significantly higher virus neutralizing antibodies in pigs. After virus challenge, VLPs-vaccinated pigs had normal body weight gain compared to Cap protein alone and commercial PCV2 vaccine groups. Virus clearance, however, was observed in equally in VLPs as well as other control vaccine groups [79].

Only a single VLPs-based vaccine study for porcine parvovirus was found [80]. PPV-VLPs expressing major structural protein VP2 were administered IM with double oil emulsion (DOE) mineral oil adjuvant to weaned pigs. There was an induction of significantly higher neutralizing antibodies in VLPs-vaccinated animals compared to inactivated vaccine group. Further, when gilts immunized with this formulation were challenged with virulent PPV, virus was not detected in any of the fetuses. Thus, PPV-VLPs can be a potential vaccine candidate to prevent PPV-induced reproductive failure [80]. In summary, VLPs of various origin can be used to develop more efficient vaccines against porcine viral infections. Further studies are needed to evaluate their immunogenicity and protective efficacy under field conditions.

\subsection{Biodegradable synthetic PLGA NPs}

PLGA is a co-polymer of lactic acid and glycolic acid. It is the most widely explored synthetic polymer in vaccine studies. It is a safe and non-toxic compound, and its hydrolysis products are readily assimilated into existing metabolic pathways [81]. PLGA nanoparticles are prepared either by oil in water emulsification or nanoprecipitation methods [82, 83]. PLGA NPs bear a net negative charge. They enter APCs through pinocytosis and endocytosis, undergo reversal of charge and endolysosomal escape of entrapped vaccine cargo leading to antigen processing in cytoplasm, resulting in cross-presentation of antigen to $\mathrm{CD}^{+} \mathrm{T}$ cells through MHC class I pathway $[59,82]$. PLGA NPs are involved in maturation of DCs of mice and human origin, and controlled release of entrapped antigens leading to efficient expansion and differentiation of memory T-cells $[84,85]$. In rodent studies, induction of robust T-cell immunity is observed with PLGA NPs-based vaccines containing various vaccine antigens [55, 82]. Further, PLGA is approved for drug deliveries in humans by the US Food and Drug Administration (FDA) and European Medicine Agency (EMA) [82].

PLGA NPs enhance antigen uptake and induce maturation of porcine APCs $[62,86,87]$. Single dose of IN immunization with PLGA NPs-encapsulated inactivated/ killed PRRSV antigen (NPs-KAg) induced activation of innate natural killer (NK) cells, $\gamma \delta$ T-cells and secretion of innate cytokine IFN $\alpha$ [86]. NPs-KAg vaccine also induced greater frequency of $\mathrm{CD}^{+} \mathrm{T}$ cells; increased secretion of IFN- $\gamma$; lowered frequency of T-regulatory cells; and reduced secretion of inflammatory cytokines compared to control KAg-vaccinated animals [86, 88]. In a subsequent study, when NPs-KAg was co-administered IN with $M$. tuberculosis WCL adjuvant, a balanced Th1/ Th2 immune response and augmentation of mucosal IgA antibody response was observed. After heterologous PRRSV challenge, pigs that received NPs-based vaccine showed no clinical signs and also had significant reduction in lung virus load $[87,89]$.

PLGA NPs were also used to encapsulate highly conserved influenza peptides and evaluated for efficacy in pigs after IN administration. PLGA NPs-based subunit 
vaccine resulted in induction of epitope-specific T-cell response but not the antibody response [61]. The T-cell biased immune response was also observed in pigs after IN immunization with PLGA NPs-encapsulated inactivated/killed influenza virus (PLGA-KAg) vaccine in pigs [62]. In PLGA-KAg vaccine administered animals observed reduced fever; lowered pneumonic lesions; and increased virus clearance from lungs after heterologous virus challenge compared to KAg vaccine controls [62].

In another study, PEDV KAg was encapsulated in PLGA NPs and used to immunize pregnant sows by IN route. This nanovaccine induced higher virus-specific IgG and neutralizing antibodies in serum and greater IgG, IgA and neutralizing antibody responses in colostrum. It also induced greater cell proliferation and IFN- $\gamma$ responses in restimulated PBMCs compared to KAg vaccine controls. Importantly, piglets born to NPs-vaccinated sows had higher virus neutralizing antibodies and were better protected against homologous virus challenge than KAg controls [90]. These studies suggest that PLGA NPs can be used as an efficient means of enhancing virus-specific cell-mediated immune responses in pigs.

\subsection{Polyanhydride-based NPs}

Polyanhydrides are another type of synthetic polymer widely studied for vaccine deliveries [91]. Polyanhydride NPs are synthesized by polycondensation or emulsification processes and are biodegradable, biocompatible and safe for vaccine delivery $[91,92]$. They activate innate immune responses in a manner similar to lipopolysaccharides (LPS) [93]. The surface-eroding nature of polyanhydride NPs provides safe microenvironment for the encapsulated antigens and facilitates slow and sustained antigen release [92, 94]. Induction of better antibody and cell-mediated immune responses by polyanhydride NPsbased vaccines has been reported against viral, bacterial and parasitic infections [48, 91]. Inoculation of polyanhydride NPs-based SIV KAg vaccine (KAg-nanovaccine) by IN route enhanced cell-mediated but not the antibody responses in pigs [64]. After heterologous virus challenge, KAg-nanovaccine group had six to eightfold reduction of nasal virus shedding compared to KAg vaccine controls [64]. In a subsequent study, when KAg-nanovaccine formulation was supplemented with CpG-ODN adjuvant, both cell-mediated as well as mucosal IgA antibody responses were improved [95]. After heterologous virus challenge, CpG-ODN-adjuvanted KAg-nanovaccine provided better protection through a significant reduction in influenza-induced fever, 16 -fold reduction of nasal virus shedding and 80-fold reduction in lung virus titers compared to pigs immunized with five-times greater quantity of soluble killed antigen (KAg) vaccine [95]. This study also indicates the dose-sparing ability of polyanhydride NPs. Thus, polyanhydride NPs can also be used to induce better cellular as well as humoral immune responses in pigs.

\subsection{Polysaccharide-based NPs}

Chitosan, alginate and other polysaccharides have also attracted attention as materials for NPs formulation and drug delivery studies. Chitosan is a natural polymer derived from deacetylation of chitin and is composed of glucosamine and $N$-acetylglucosamine residues [96]. Due to the availability of amino and carboxyl groups in an acidic microenvironment, chitosan NPs have net positive surface charge which makes them highly mucoadhesive and increases their half-time of antigen retention on mucosal surfaces $[97,98]$. Further, chitosan NPs can reversibly open the epithelial cell tight junctions thereby improving paracellular and intracellular antigen transport across mucosal epithelial surfaces [99, 100]. Chitosan NPs also enhance antigen uptake by APCs, induce APC maturation and active secretion of innate cytokines $[101,102]$. Thus, chitosan NPs form an attractive mucosal vaccine delivery vehicle.

Chitosan-based NPs are used in pigs to deliver adjuvants such as bee venom and plasmid encoding porcine IL-2 and IL-4/IL-6 genes, which improved induction of better virus-specific immune responses of respective vaccines against PRRSV and PCV2 [103, 104]. Chitosan NPs enhance antigen uptake by porcine APCs and activate them to produce innate cytokines including IFN-alpha, TNF-alpha and IL-1 $\beta$ [105]. Chitosan NPs encapsulated SIV KAg (CNPs-KAg) vaccine administered twice through IN route without any additional adjuvant in pigs induced the cross-reactive mucosal IgA antibodies. Chitosan NPs-based vaccine also induced IFN- $\gamma$ response in PBMCs and tracheobronchial lymph nodes (TBLN) better than KAg vaccine controls. This vaccine formulation substantially reduced the challenge heterologous virus titers by up to 100 -fold in both the upper and lower respiratory tracts compared to soluble KAg vaccine. This finding emphasizes the potential benefits of using Chitosan NPs in future development of mucosal swine influenza vaccine for pigs [105].

Recently, dendrimer-like-alpha-D-glucan (Nano-11) NPs derived from sweet corn variety sugary-1 was examined as an alternative, safe, cost-effective and potent adjuvant $[106,107]$. Nano-11 are positively charged NPs which efficiently adsorb negatively charged antigens through electrostatic interactions. Rodent studies have shown that Nano-11 NPs enhance antigen uptake by DCs, induce their maturation, activate them to produce pro-inflammatory cytokines and help in induction of antigen-specific antibodies [106, 107]. In a recent study, 
we observed that Nano-11 NPs with or without addition of SIV killed antigen (KAg) can stimulate porcine APCs and produce cytokines such as IFN- $\alpha$, TNF- $\alpha$ and IL- $1 \beta$ [108]. Pigs immunized via IN route with Nano-11 NPs adsorbed SIV KAg at two-to-one ratio (Nano-11+ KAg) resulted in cross-reactive mucosal IgA responses better than KAg controls. Moreover, pigs immunized IM with Nano-11 adsorbed ovalbumin (Nano-11+OVA) had significantly greater IgG1 and IgG2 antibodies in serum compared with pigs vaccinated with OVA alone [108]. These findings highlight the possibility of using cornderived Nano-11 NPs as a potential adjuvant in porcine viral vaccine development.

\subsection{Liposome-based NPs}

Liposomes can encapsulate both hydrophilic and hydrophobic molecules in aqueous and non-aqueous phases of their vesicles [109]. Liposome vesicles protect antigens from enzymatic degradation, enhance antigen internalization by APCs and maintain controlled release of antigens [110]. Liposome-encapsulated antigens can enhance both cellular and humoral immune responses $[110,111]$. In a pig study, liposome NPs were used as an IM adjuvant for a PCV2 DNA vaccine [112]. Liposome NPs-adjuvant induced higher neutralizing antibodies and IFN $\gamma$ response in pigs and reduced viremia of a challenge virus compared to alum-adjuvanted vaccine, providing the evidence that liposome NPs can be a potent adjuvant in pigs [112]. In our recent study, we used liposome NPs to encapsulate ten highly conserved peptides of different influenza viruses of human and pig origin and immunized pigs through IN route co-administered with monosodium urate (MSU) crystal adjuvant [113]. The liposome-adjuvant based vaccine enhanced the mucosal IgA antibody response and induced peptide and virusspecific T-helper/memory cells and IFN $\gamma$ responses resulting in reduced fever and modest reduction in virus titers in the respiratory tract of pigs [113]. These studies highlight the fact that liposome-based NPs can be used as an attractive vaccine delivery platform against porcine viral infections.

\section{Conclusions and future perspectives}

Virus infections have significant impact on pig industry worldwide. Use of available vaccines have definitely helped in achieving strong control over some of the porcine viral infections such as Food and Mouth Disease, Transmissible Gastroenteritis, Classical Swine Fever and Pseudorabies. Vaccination also helped in reducing the clinical signs and increasing the production parameters in PCV2-associated disease. However, for many other porcine viruses, further improvements in existing vaccine platforms and development of novel vaccine delivery systems are necessary to: (1) Induce better mucosal and cell-mediated immunity; (2) Protect against emerging and re-emerging strains; (3) Enhance the breadth (heterologous, cross-genotype and heterosubtypic) of immunity; and (4) Differentiate between infected and vaccinated animals.

NPs-based vaccine delivery platforms such as VLPs, biodegradable polymers and liposomes have great potential as they-(1) Protect vaccine antigens from degradation; (2) Facilitate antigen uptake and processing by APCs; (3) Impart adjuvant potential; (4) Can be used in mucosal and other alternate routes of immunizations; and (5) Induce effective mucosal and cellular cross-protective (broader) immunity. Research efforts are ongoing to develop porcine viral vaccines using NPs-based technologies. However, more collaboration(s) and in-depth studies are warranted to make this innovative vaccine antigen delivery technology successful and practical for application in food animal industry. To date, almost all of the immunomodulatory mechanisms of NPs-based vaccine delivery platforms have been studied in rodent disease models, which may or may not reflect the situation in pigs or other domestic animal species [114]. Likewise, proper understanding of effect of size, charge and other physicochemical properties of NPs after delivery through different routes of immunization in pigs is necessary to make efficient translation of this robust NPs-based vaccine technology. Similarly, studies should also focus on NPs stability at different storage conditions and immunogenicity over a long period of time as they will directly associate with commercial aspect of the vaccine product. Recent advances in NPs-based adjuvant and vaccine delivery platforms in pigs demonstrate great promise to yield better candidate vaccines against many porcine viral infections with enhanced efficacy in the field. These nanovaccine technologies can also be adopted to develop effective vaccines against viral infections in other animal species, and knowledge gained could be exploited for improving the efficacy of existing human viral vaccines.

\begin{abstract}
Acknowledgements
The research reviewed in this article was supported by Agriculture and Food Research Initiative Competitive Grant no. 2013-67015-20476 from the USDANIFA and Nanovaccine Institute (2015-2018), lowa state University to RGJ. Salaries and research supports were provided by the state and federal funds appropriated to OARDC. We thank Dr. Steven Krakowka for scientific editing of the manuscript.
\end{abstract}

\section{Authors' contributions}

SD wrote the article; GJR edited and revised the article. Both authors read and approved the final manuscript.

Competing interests

The authors declare that they have no competing interests.

Author details

${ }^{1}$ Food Animal Health Research Program, Ohio Agricultural Research and Development Center, 1680 Madison Avenue, Wooster, OH 44691, USA. 
${ }^{2}$ Department of Veterinary Preventive Medicine, College of Veterinary Medicine, The Ohio State University, Columbus, OH 43210, USA.

\section{Received: 28 April 2019 Accepted: 20 October 2019}

Published online: 06 November 2019

\section{References}

1. Straub OC (1994) The important viral infections of pigs. Swine Health Prod 2:15-18

2. Meng XJ (2012) Emerging and re-emerging swine viruses. Transbound Emerg Dis 59(Suppl 1):85-102

3. Lunney JK, Fang Y, Ladinig A, Chen N, Li Y, Rowland B, Renukaradhya GJ (2016) Porcine reproductive and respiratory syndrome virus (PRRSV): pathogenesis and interaction with the immune system. Annu Rev Anim Biosci 4:129-154

4. Holtkamp DJ, Kliebenstein JB, Neumann EJ, Zimmerman JJ, Rotto HF, Yoder TK, Wang C, Yeske PE, Mowrer CL, Haley CA (2013) Assessment of the economic impact porcine reproductive and respiratory syndrome virus on United States pork producers. J Swine Health Prod 21:72-84

5. Sandbulte MR, Spickler AR, Zaabel PK, Roth JA (2015) Optimal use of vaccines for control of influenza A virus in swine. Vaccines 3:22-73

6. Haden C, Painter T, Fangman T, Holtkamp D (2012) Assessing production parameters and economic impact of swine influenza, PRRS and Mycoplasma hyopneimoniae on finishing pigs in a large production system. In: Proceedings of AASV annual meeting, pp 75-76

7. Hass J, Matuszewski S, Cieslik D, Haase M (2011) The role of swine as "mixing vessel" for interspecies transmission of the influenza A subtype H1N1: a simultaneous Bayesian inference of phylogeny and ancestral hosts. Infect Genet Evol 11:437-441

8. Gerdts V, Zakhartchouk A (2017) Vaccines for porcine epidemic diarrhea virus and other swine coronaviruses. Vet Microbiol 206:45-51

9. Langel SN, Paim FC, Lager KM, Vlasova AN, Saif LJ (2016) Lactogenic immunity and vaccines for porcine epidemic diarrhea virus (PEDV): historical and current concepts. Virus Res 226:93-107

10. Vlasova AN, Amimo JO, Saif LJ (2017) Porcine rotaviruses: epidemiology, immune responses and control strategies. Viruses 9:E48

11. Stenfeldt C, Diaz-San Segundo F, de Los Santos T, Rodriguez LL, Arzt J (2016) The pathogenesis of foot-and-mouth disease in pigs. Front Vet Sci 3:41

12. Brown VR, Bevins SN (2018) A review of classical swine fever virus and routes of introduction into the United States and the potential for virus establishment. Front Vet Sci 5:31

13. Schulz K, Staubach C, Blome S (2017) African and classical swine fever: similarities, differences and epidemiological consequences. Vet Res 48:84

14. Elber AR, Stegeman A, Moser H, Ekker HM, Smak JA, Pluimers FH (1999) The classical swine fever epidemic 1997-1998 in The Netherlands: descriptive epidemiology. Prev Vet Med 42:157-184

15. Rose N, Opriessnig T, Grasland B, Jestin A (2012) Epidemiology and transmission of porcine circovirus type 2 (PCV2). Virus Res 164:78-89

16. Karuppannan AK, Opriessnig T (2017) Porcine circovirus type 2 (PCV2) vaccines in the context of current molecular epidemiology. Viruses 9:E99

17. Streck AF, Canal CW, Truyen U (2015) Molecular epidemiology and evolution of porcine parvoviruses. Infect Genet Evol 36:300-306

18. Muller T, Hahn EC, Tottewitz F, Kramer M, Klupp BG, Mettenleiter TC, Freuling C (2011) Pseudorabies virus in wild swine: a global perspective. Arch Virol 156:1691-1705

19. Freuling CM, Muller TF, Mettenleiter TC (2017) Vaccines against pseudorabies virus (PrV). Vet Microbiol 206:3-9

20. Brown VR, Bevins SN (2018) A review of African swine fever and the potential for introduction into the United States and the possibility of subsequent establishment in feral swine and native ticks. Front Vet Sci $5: 11$

21. Jeoung HY, Lee $W H$, Jeong W, Shin BH, Choi HW, Lee HS, An DJ (2011) Immunogenicity and safety of virus-like particle of the porcine encephalomyocarditis virus in pig. Virol J 8:170

22. Fan YC, Chen JM, Lin JW, Chen YY, Wu GH, Su KH, Chiou MT, Wu SR, Yin JH, Liao JW, Chang GJ, Chiou SS (2018) Genotype I of Japanese encephalitis virus virus-like particles elicit sterilizing immunity against genotype I and III viral challenge in swine. Sci Rep 8:7481

23. Nan Y, Wu C, Gu G, Sun W, Zhang YJ, Zhou EM (2017) Improved vaccine against PRRSV: current progress and future perspective. Front Microbiol 8:1635

24. Kimman TG, Cornelissen LA, Moormann RJ, Rebel JM, Stockhofe-Zurwieden N (2009) Challenges for porcine reproductive and respiratory syndrome virus (PRRSV) vaccinology. Vaccine 27:3704-3718

25. Renukaradhya GJ, Meng XJ, Calvert JG, Roof M, Lager KM (2015) Live porcine reproductive and respiratory syndrome virus vaccines: current status and future direction. Vaccine 33:4069-4080

26. Renukaradhya GJ, Meng XJ, Calvert JG, Roof M, Lager KM (2015) Inactivated and subunit vaccines against porcine reproductive and respiratory syndrome: current status and future direction. Vaccine 33:3065-3072

27. Renukaradhya GJ, Dwivedi V, Manickam C, Binjawadagi B, Benfield D (2012) Mucosal vaccines to prevent porcine reproductive and respiratory syndrome: a new perspective. Anim Health Res Rev 13:21-37

28. Vincent AL, Perez DR, Rajao D, Anderson TK, Abente EJ, Walia RR, Lewis NS (2017) Influenza A virus vaccines for swine. Vet Microbiol 206:35-44

29. Diaz-San Segundo F, Medina GN, Stenfeldt C, Arzt J, de Los Santos T (2017) Foot-and-mouth disease vaccines. Vet Microbiol 206:102-112

30. Blome S, Moss C, Reimann I, Konig P, Beer M (2017) Classical swine fever vaccines-state-of-the-art. Vet Microbiol 206:10-20

31. Afghah Z, Webb B, Meng XJ, Ramamoorthy S (2017) Ten years of PCV2 vaccines and vaccination: is eradication a possibility? Vet Microbiol 206:21-28

32. Xiao CT, Harmon KM, Halbur PG, Opriessnig T (2016) PCV2d-2 is the predominant type of PCV2 DNA in pig samples collected in the U.S. during 2014-2016. Vet Microbiol 197:72-77

33. Meszaros I, Olasz F, Csagola A, Tijssen P, Zadori Z (2017) Biology of porcine parvovirus (Ungulate parvovirus 1). Viruses 9:E393

34. Sun Y, Luo Y, Wang CH, Yuan J, Li N, Song K, Qiu HJ (2016) Control of swine pseudorabies in China: opportunities and limitations. Vet Microbiol 183:119-124

35. Sanchez-Cordon PJ, Montoya M, Reis AL, Dixon LK (2018) African swine fever: a re-emerging viral disease threatening the global pig industry. Vet J 233:41-48

36. Andre FE, Booy R, Bock HL, Clemens J, Datta SK, John TJ, Lee BW, Lolekha S, Peltola H, Ruff TA, Santosham M, Schmitt HJ (2008) Vaccination greatly reduces disease, disability, death and inequity worldwide. Bull World Health Organ 86:140-146

37. Roth JA (2011) Veterinary vaccines and their importance to animal health and public health. Procedia Vaccinol 5:127-136

38. Demento SL, Cui W, Criscione JM, Stern E, Tulipan J, Kaech SM, Fahmy TM (2012) Role of sustained antigen release from nanoparticle vaccines in shaping the $T$ cell memory phenotype. Biomaterials 33:4957-4964

39. Akagi T, Baba M, Akashi M (2012) Biodegradable nanoparticles as vaccine adjuvants and delivery systems: regulation of immune responses by nanoparticle-based vaccine. In: Kunugi S, Yamaoka T (eds) Polymers in nanomedicine. Springer, Berlin, pp 31-64

40. Joshi VB, Geary SM, Salem AK (2013) Biodegradable particles as vaccine delivery systems: size matters. AAPS J 15:85-94

41. Aoshi T (2017) Modes of action for mucosal vaccine adjuvants. Viral Immunol 30:463-470

42. Coffman RL, Sher A, Seder RA (2010) Vaccine adjuvants: putting innate immunity to work. Immunity 33:492-503

43. Kool M, Fierens K, Lambrecht BN (2012) Alum adjuvant: some of the tricks of the oldest adjuvant. J Med Microbiol 61:927-934

44. Hogenesch H (2012) Mechanism of immunopotentiation and safety of aluminum adjuvants. Front Immunol 3:406

45. Spickler AR, Roth JA (2003) Adjuvants in veterinary vaccines: modes of action and adverse effects. J Vet Intern Med 17:273-281

46. Gerdts V (2015) Adjuvants for veterinary vaccines - types and modes of action. Berl Munch Tierarztl Wochenschr 128:456-463

47. Lycke N (2012) Recent progress in mucosal vaccine development: potential and limitations. Nat Rev Immunol 12:592-605 
48. Renukaradhya GJ, Narasimhan B, Mallapragada SK (2015) Respiratory nanoparticle-based vaccines and challenges associated with animal models and translation. J Control Release 219:622-631

49. Wen ZS, Xu YL, Zou XT, Xu ZR (2011) Chitosan nanoparticles act as an adjuvant to promote both Th1 and Th2 immune responses induced by ovalbumin in mice. Mar Drugs 9:1038-1055

50. Tamayo I, Irache JM, Mansilla C, Ochoa-Reparaz J, Lasarte JJ, Gamazo C (2010) Poly(anhydride) nanoparticles act as active Th1 adjuvants through Toll-like receptor exploitation. Clin Vaccine Immunol 17:1356-1362

51. Tandrup Schmidt S, Foged C, Smith Korsholm K, Rades T, Christensen D (2016) Liposome-based adjuvants for subunit vaccines: formulation strategies for subunit antigens and immunostimulators. Pharmaceutics 8:E7

52. Gregory AE, Titball R, Williamson D (2013) Vaccine delivery using nanoparticles. Front Cell Infect Microbiol 3:13

53. Zhang XQ, Dahle CE, Baman NK, Rich N, Weiner GJ, Salem AK (2007) Potent antigen-specific immune responses stimulated by codelivery of CpG ODN and antigens in degradable microparticles. J Immunother 30:469-478

54. Diwan M, Tafaghodi M, Samuel J (2002) Enhancement of immune responses by co-delivery of a $\mathrm{CpG}$ oligodeoxynucleotide and tetanus toxoid in biodegradable nanospheres. J Control Release 85:247-262

55. Hamdy S, Molavi O, Ma Z, Haddadi A, Alshamsan A, Gobti Z, Elhasi S, Samuel J, Lavasanifar A (2008) Co-delivery of cancer-associated antigen and Toll-like receptor 4 ligand in PLGA nanoparticles induces potent CD8+ T cell-mediated anti-tumor immunity. Vaccine 26:5046-5057

56. Gupta PN, Khatri K, Goyal AK, Mishra N, Vyas SP (2007) M-cell targeted biodegradable PLGA nanoparticles for oral immunization against hepatitis B. J Drug Target 15:701-713

57. Raghuwanshi D, Mishra V, Das D, Kaur K, Suresh MR (2012) Dendritic cell targeted chitosan nanoparticles for nasal DNA immunization against SARS CoV nucleocapsid protein. Mol Pharm 9:946-956

58. Panyam J, Zhou WZ, Prabha S, Sahoo SK, Labhasetwar V (2002) Rapid endo-lysosomal escape of poly(DL-lactide-co-glycolide) nanoparticles: implications for drug and gene delivery. FASEB J 16:1217-1226

59. Shen H, Ackerman AL, Cody V, Giodini A, Hinson ER, Cresswell P, Edelson RL, Saltzman WM, Hanlon DJ (2006) Enhanced and prolonged crosspresentation following endosomal escape of exogenous antigens encapsulated in biodegradable nanoparticles. Immunology 117:78-88

60. Herrmann VL, Hartmayer C, Planz O, Groettrup M (2015) Cytotoxic T cell vaccination with PLGA microspheres interferes with influenza A virus replication in the lung and suppresses the infectious disease. J Control Release 216:121-131

61. Hiremath J, Kang Kl, Xia M, Elaish M, Binjawadagi B, Ouyang K, Dhakal S, Arcos J, Torrelles JB, Jiang X, Lee CW, Renukaradhya GJ (2016) Entrapment of H1N1 influenza virus derived conserved peptides in PLGA nanoparticles enhances $T$ cell response and vaccine efficacy in pigs. PLoS One 11:e0151922

62. Dhakal S, Hiremath J, Bondra K, Lakshmanappa YS, Shyu DL, Ouyang K, Kang Kl, Binjawadagi B, Goodman J, Tabynov K, Krakowka S, Narasimhan B, Lee CW, Renukaradhya GJ (2017) Biodegradable nanoparticle delivery of inactivated swine influenza virus vaccine provides heterologous cell-mediated immune response in pigs. J Control Release 247:194-205

63. Lee Y-R, Lee Y-H, Kim K-H, Im S-A, Lee C-K (2013) Induction of potent antigen-specific cytotoxic T cell response by PLGA-nanoparticles containing antigen and TLR agonist. Immune Netw 13:30-33

64. Dhakal S, Goodman J, Bondra K, Lakshmanappa YS, Hiremath J, Shyu DL, Ouyang K, Kang KI, Krakowka S, Wannemuehler MJ, Won Lee C, Narasimhan B, Renukaradhya GJ (2017) Polyanhydride nanovaccine against swine influenza virus in pigs. Vaccine 35:1124-1131

65. Kushnir N, Streatfield SJ, Yusibov V (2012) Virus-like particles as a highly efficient vaccine platform: diversity of targets and production systems and advances in clinical development. Vaccine 31:58-83

66. Ding X, Liu D, Booth G, Gao W, Lu Y (2018) Virus-like particle engineering: from rational design to versatile applications. Biotechnol J 13:e1700324

67. Harding CV, Song R (1994) Phagocytic processing of exogenous particulate antigens by macrophages for presentation by class I MHC molecules. J Immunol 153:4925-4933
68. Kovacsovics-Bankowski M, Clark K, Benacerraf B, Rock KL (1993) Efficient major histocompatibility complex class I presentation of exogenous antigen upon phagocytosis by macrophages. Proc Natl Acad Sci U S A 90:4942-4946

69. Mohsen MO, Zha L, Cabral-Miranda G, Bachmann MF (2017) Major findings and recent advances in virus-like particle (VLP)-based vaccines. Semin Immunol 34:123-132

70. Binjawadagi B, Lakshmanappa YS, Longchao Z, Dhakal S, Hiremath J, Ouyang K, Shyu DL, Arcos J, Pengcheng S, Gilbertie A, Zuckermann F, Torrelles JB, Jackwood D, Fang Y, Renukaradhya GJ (2016) Development of a porcine reproductive and respiratory syndrome virus-like-particlebased vaccine and evaluation of its immunogenicity in pigs. Arch Virol 161:1579-1589

71. Van Noort A, Nelsen A, Pillatzki AE, Diel DG, Li F, Nelson E, Wang X (2017) Intranasal immunization of pigs with porcine reproductive and respiratory syndrome virus-like particles plus 2', 3'-cGAMP VacciGrade adjuvant exacerbates viremia after virus challenge. Virol J 14:76

72. Pyo HM, Masic A, Woldeab N, Embury-Hyatt C, Lin L, Shin YK, Song JY, Babiuk S, Zhou Y (2012) Pandemic H1N1 influenza virus-like particles are immunogenic and provide protective immunity to pigs. Vaccine 30:1297-1304

73. Crisci E, Fraile L, Moreno N, Blanco E, Cabezon R, Costa C, Mussa T, Baratelli M, Martinez-Orellana P, Ganges L, Martinez J, Barcena J, Montoya M (2012) Chimeric calicivirus-like particles elicit specific immune responses in pigs. Vaccine 30:2427-2439

74. Guo HC, Sun SQ, Jin Y, Yang SL, Wei YQ, Sun DH, Yin SH, Ma JW, Liu ZX, Guo JH, Luo JX, Yin H, Liu XT, Liu DX (2013) Foot-and-mouth disease virus-like particles produced by a SUMO fusion protein system in Escherichia coli induce potent protective immune responses in guinea pigs, swine and cattle. Vet Res 44:48

75. Dong YM, Zhang GG, Huang XJ, Chen L, Chen HT (2015) Promising MS2 mediated virus-like particle vaccine against foot-and-mouth disease. Antiviral Res 117:39-43

76. Pan Q, Wang H, Ouyang W, Wang X, Bi Z, Xia X, Wang Y, He K (2016) Immunogenicity of adenovirus-derived porcine parvovirus-like particles displaying B and T cell epitopes of foot-and-mouth disease. Vaccine 34:578-585

77. Wu PC, Lin WL, Wu CM, Chi JN, Chien MS, Huang C (2012) Characterization of porcine circovirus type 2 (PCV2) capsid particle assembly and its application to virus-like particle vaccine development. Appl Microbiol Biotechnol 95:1501-1507

78. Li W, Wang X, Bai J, Ma T, Li Z, Li Y, Jiang P (2013) Construction and immunogenicity of recombinant porcine circovirus-like particles displaying somatostatin. Vet Microbiol 163:23-32

79. Zhang H, Qian P, Peng B, Shi L, Chen H, Li X (2015) A novel subunit vaccine co-expressing GM-CSF and PCV2b Cap protein enhances protective immunity against porcine circovirus type 2 in piglets. Vaccine 33:2449-2456

80. Antonis AF, Bruschke CJ, Rueda P, Maranga L, Casal Jl, Vela C, Hilgers LA, Belt PB, Weerdmeester K, Carrondo MJ, Langeveld JP (2006) A novel recombinant virus-like particle vaccine for prevention of porcine parvovirus-induced reproductive failure. Vaccine 24:5481-5490

81. Makadia HK, Siegel SJ (2011) Poly lactic-co-glycolic acid (PLGA) as biodegradable controlled drug delivery carrier. Polymers 3:1377-1397

82. Danhier F, Ansorena E, Silva JM, Coco R, Le Breton A, Preat V (2012) PLGA-based nanoparticles: an overview of biomedical applications. J Control Release 161:505-522

83. Scholes PD, Coombes AGA, Illum L, Daviz SS, Vert M, Davies MC (1993) The preparation of sub-200 $\mathrm{nm}$ poly(lactide-co-glycolide) microspheres for site-specific drug delivery. J Control Release 25:145-153

84. Clawson C, Huang CT, Futalan D, Seible DM, Saenz R, Larsson M, Ma W, Minev B, Zhang F, Ozkan M, Ozkan C, Esener S, Messmer D (2010) Delivery of a peptide via poly(D, L-lactic-co-glycolic) acid nanoparticles enhances its dendritic cell-stimulatory capacity. Nanomedicine 6:651-661

85. Blair DA, Turner DL, Bose TO, Pham QM, Bouchard KR, Williams KJ McAleer JP, Cauley LS, Vella AT, Lefrancois L (2011) Duration of antigen availability influences the expansion and memory differentiation of $\mathrm{T}$ cells. J Immunol 187:2310-2321

86. Dwivedi V, Manickam C, Binjawadagi B, Joyappa D, Renukaradhya GJ (2012) Biodegradable nanoparticle-entrapped vaccine induces 
cross-protective immune response against a virulent heterologous respiratory viral infection in pigs. PLoS One 7:e51794

87. Binjawadagi B, Dwivedi V, Manickam C, Ouyang K, Wu Y, Lee LJ, Torrelles JB, Renukaradhya GJ (2014) Adjuvanted poly(lactic-co-glycolic) acid nanoparticle-entrapped inactivated porcine reproductive and respiratory syndrome virus vaccine elicits cross-protective immune response in pigs. Int J Nanomedicine 9:679-694

88. Dwivedi V, Manickam C, Binjawadagi B, Renukaradhya GJ (2013) PLGA nanoparticle entrapped killed porcine reproductive and respiratory syndrome virus vaccine helps in viral clearance in pigs. Vet Microbiol 166:47-58

89. Binjawadagi B, Dwivedi V, Manickam C, Ouyang K, Torrelles JB, Renukaradhya GJ (2014) An innovative approach to induce cross-protective immunity against porcine reproductive and respiratory syndrome virus in the lungs of pigs through adjuvanted nanotechnology-based vaccination. Int J Nanomedicine 9:1519-1535

90. Li B, Du L, Yu Z, Sun B, Xu X, Fan B, Guo R, Yuan W, He K (2017) Poly (d, I-lactide-co-glycolide) nanoparticle-entrapped vaccine induces a protective immune response against porcine epidemic diarrhea virus infection in piglets. Vaccine 35:7010-7017

91. Basu A, Domb AJ (2018) Recent advances in polyanhydride based biomaterials. Adv Mater 30:e1706815

92. Torres MP, Determan AS, Anderson GL, Mallapragada SK, Narasimhan B (2007) Amphiphilic polyanhydrides for protein stabilization and release. Biomaterials 28:108-116

93. Petersen LK, Ramer-Tait AE, Broderick SR, Kong CS, Ulery BD, Rajan K, Wannemuehler MJ, Narasimhan B (2011) Activation of innate immune responses in a pathogen-mimicking manner by amphiphilic polyanhydride nanoparticle adjuvants. Biomaterials 32:6815-6822

94. Ross KA, Loyd H, Wu W, Huntimer L, Wannemuehler MJ, Carpenter S, Narasimhan B (2014) Structural and antigenic stability of H5N1 hemagglutinin trimer upon release from polyanhydride nanoparticles. $J$ Biomed Mater Res A 102:4161-4168

95. Dhakal S, Ghimire S, Renu S, Ross KA, Lakshmanappa YS, Hogshead BT, Bernardo P, Lee CW, Wannemuehler MJ, Narasimhan B, Renukaradhya GJ (2019) Evaluation of CpG-ODN-adjuvanted polyanhydride-based intranasal influenza nanovaccine in pigs. Vet Microbiol 237:108401

96. Hejazi R, Amiji M (2003) Chitosan-based gastrointestinal delivery systems. J Control Release 89:151-165

97. Lee DW, Lim C, Israelachvili JN, Hwang DS (2013) Strong adhesion and cohesion of chitosan in aqueous solutions. Langmuir 29:14222-14229

98. Lim C, Lee DW, Israelachvili JN, Jho Y, Hwang DS (2015) Contact timeand $\mathrm{pH}$-dependent adhesion and cohesion of low molecular weight chitosan coated surfaces. Carbohydr Polym 117:887-894

99. Artursson P, LindmarkT, Davis SS, Illum L (1994) Effect of chitosan on the permeability of monolayers of intestinal epithelial cells (Caco-2). Pharm Res 11:1358-1361

100. Dodane V, Amin Khan M, Merwin JR (1999) Effect of chitosan on epithelial permeability and structure. Int J Pharm 182:21-32

101. Bp Koppolu, Zaharoff DA (2013) The effect of antigen encapsulation in chitosan particles on uptake, activation and presentation by antigen presenting cells. Biomaterials 34:2359-2369

102. Hunsawong T, Sunintaboon P, Warit S, Thaisomboonsuk B, Jarman RG, Yoon IK, Ubol S, Fernandez S (2015) Immunogenic properties of a BCG adjuvanted chitosan nanoparticle-based denque vaccine in human dendritic cells. PLoS Negl Trop Dis 9:e0003958
103. Lee J, Kim YM, Kim JH, Cho CW, Jeon JW, Park JK, Lee SH, Jung BG, Lee BJ (2018) Nasal delivery of chitosan/alginate nanoparticle encapsulated bee (Apis mellifera) venom promotes antibody production and viral clearance during porcine reproductive and respiratory syndrome virus infection by modulating T cell related responses. Vet Immunol Immunopathol 200:40-51

104. Chen Y, Song T, Xiao YL, Wan X, Yang L, Li J, Zeng G, Fang P, Wang ZZ, Gao R (2018) Enhancement of immune response of piglets to PCV-2 vaccine by porcine IL-2 and fusion IL-4/6 gene entrapped in chitosan nanoparticles. Res Vet Sci 117:224-232

105. Dhakal S, Renu S, Ghimire S, Shaan Lakshmanappa Y, Hogshead BT, Feliciano-Ruiz N, Lu F, HogenEsch H, Krakowka S, Lee CW, Renukaradhya GJ (2018) Mucosal immunity and protective efficacy of intranasal inactivated influenza vaccine is improved by chitosan nanoparticle delivery in pigs. Front Immunol 9:934

106. Lu F, Mosley YYYC, Rodriguez Rosales RJ, Carmichael BE, Elesela S, Yao Y, HogenEsch H (2017) Alpha-D-glucan nanoparticulate adjuvant induces a transient inflammatory response at the injection site and targets antigen to migratory dendritic cells. NPJ Vaccines $2: 4$

107. Lu F, Mencia A, Bi L, Taylor A, Yao Y, HogenEsch H (2015) Dendrimer-like alpha-D-glucan nanoparticles activate dendritic cells and are effective vaccine adjuvants. J Control Release 204:51-59

108. Dhakal S, Lu F, Ghimire S, Renu S, Lakshmanappa YS, Hogshead BT, Ragland D, HogenEsch H, Renukaradhya GJ (2019) Corn-derived alphaD-glucan nanoparticles as adjuvant for intramuscular and intranasal immunization in pigs. Nanomedicine 16:226-235

109. Schwendener RA (2014) Liposomes as vaccine delivery systems: a review of the recent advances. Ther Adv Vaccines 2:159-182

110. Bernasconi V, Norling K, Bally M, Hook F, Lycke NY (2016) Mucosal vaccine development based on liposome technology. J Immunol Res 2016:5482087

111. Harding CV, Collins DS, Slot JW, Geuze HJ, Unanue ER (1991) Liposomeencapsulated antigens are processed in lysosomes, recycled, and presented to T cells. Cell 64:393-401

112. Park C, Jeong J, Choi K, Park SJ, Kang I, Chae C (2017) Development of porcine circovirus 2 (PCV2) open reading frame 2 DNA vaccine with different adjuvants and comparison with commercial PCV2 subunit vaccine in an experimental challenge. Can J Vet Res 81:171-177

113. Dhakal S, Cheng X, Salcido J, Renu S, Bondra K, Lakshmanappa YS, Misch C, Ghimire S, Feliciano-Ruiz N, Hogshead B, Krakowka S, Carson K, McDonough J, Lee CW, Renukaradhya GJ (2018) Liposomal nanoparticle-based conserved peptide influenza vaccine and monosodium urate crystal adjuvant elicit protective immune response in pigs. Int J Nanomedicine 13:6699-6715

114. Renu S, Dhakal S, Kim E, Goodman J, Lakshmanappa YS, Wannemuehler MJ, Narasimhan B, Boyaka PN, Renukaradhya GJ (2018) Intranasal delivery of influenza antigen by nanoparticles, but not NKT-cell adjuvant differentially induces the expression of B-cell activation factors in mice and swine. Cell Immunol 329:27-30

115. Lee C (2015) Porcine epidemic diarrhea virus: an emerging and reemerging epizootic swine virus. Virol J 12:193

\section{Publisher's Note}

Springer Nature remains neutral with regard to jurisdictional claims in published maps and institutional affiliations. 